Journal of Materials and Environmental Sciences ISSN : 2028-2508

CODEN : JMESCN

Copyright $\odot 2017$

University of Mohammed Premier Oujda Morocco
J. Mater. Environ. Sci., 2017, Volume 8, Issue 12, Page 44523-4531

http://www.jmaterenvironsci.com

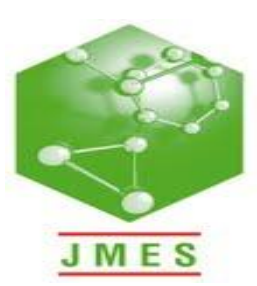

\title{
Removal of Chlorothalonil from water by a bentonite treated chemically
}

\author{
N. Boudouara ${ }^{1}$, R. Marouf ${ }^{1}$, F. Ouadjenia ${ }^{1}$, J. Schott $^{2}$ \\ ${ }^{1}$ Laboratory of Materials, Applications and Environment, University Mustapha Stambouli, B.P. 763 Mamounia road, \\ Mascara 29000, Algeria. \\ ${ }^{2}$ Laboratoire Géosciences Environnement Toulouse, CNRS (UMR 5563)-OMP-Université Paul-Sabatier, Toulouse, France.
}

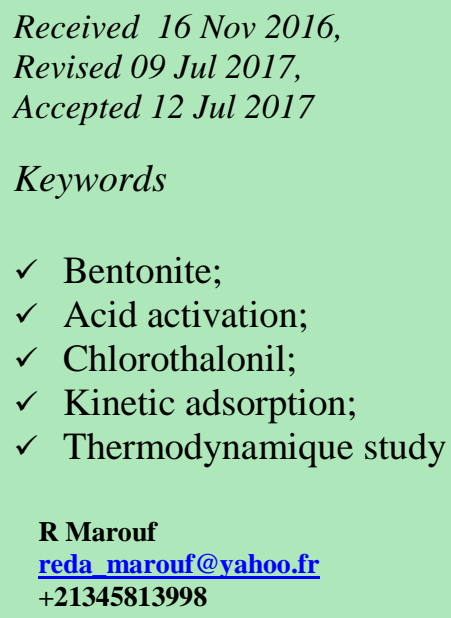

Received 16 Nov 2016,

Revised 09 Jul 2017 ,

Accepted 12 Jul 2017

Keywords

$\checkmark$ Bentonite;

$\checkmark$ Acid activation;

$\checkmark$ Chlorothalonil;

$\checkmark$ Kinetic adsorption;

$\checkmark$ Thermodynamique study

R Marouf

redamarouf@yahoo.fr

$+21345813998$

\begin{abstract}
The adsorption of Chlorothalonil fungicide from aqueous solution onto raw and activated bentonite samples was investigated as a function of parameters such as $\mathrm{pH}$, contact time, and temperature. The acid activation of natural bentonite was performed by treatment with hydrochloric solution of different concentrations. The high adsorption capacity of chlorothalonil was obtained by activated bentonite at $323 \mathrm{~K}$ in the range of $\mathrm{pH} \mathrm{3-4}$ for 60 min of contact time. It was be 32.01 and 42.88 $\mathrm{mg} / \mathrm{g}$ for raw and bentonite activated by $1 \mathrm{~N}$ hydrochloric acid, respectively. The Langmuir and Freundlich adsorption models were applied to describe the related isotherms. Freundlich equation has shown the best fitting with the experimental data. The pseudo-first order and pseudo-second order kinetic models were used to describe the kinetic data. The changes of enthalpy, entropy and Gibbs free energy of adsorption process were determined. The results indicated that the adsorption of chlorothalonil occurs spontaneously as an endothermic process.
\end{abstract}

\section{Introduction}

The use of pesticides (insecticides, herbicides, fungicides, etc.), has been necessary to improve the yields of cultivated land to meet the nutritional demand due of the increasing in world population. However, the vast use of these substances causes indirect and adverse effects on the environment. The studies indicated the presence of pesticide residues in food and the contamination of surface and groundwater [1-3].

Various techniques have been used for the removal of this type of soluble pollutants in water or soil, such as adsorption [4], electrolysis [5], electro sorption [6], precipitation [7], ion exchange [8], photocatalysis [9], membrane filtration $[10,11]$ etc. The adsorption on natural, abundant and widely available materials such as clays and bentonites greatly increases the power of pollutant removal and the treatment of contaminated water rates. Acid activation of clay minerals is one of the most effective methods that have been used to produce active materials for adsorption and catalysis proposes. This consists of the treatment of clay with a mineral acid solution, usually hydrochloric or sulphuric acids. The main goal of this process is to obtain partly dissolved material of high specific surface area, porosity and surface acidity [12,13].

Bentonite consists predominately of montmorillonite, a 2:1 clay mineral containing an octahedral sheet between two tetrahedral sheets. Activation proceeds with partial dissolution of montmorillonite and includes an initial replacement of the interlayer cations by $\mathrm{H}^{+}$, which is followed by dissolution of the octahedral and tetrahedral sheets, with subsequent release of structural cations. This attack alters the structure, chemical composition and physical properties of the clay while enhancing the adsorption capacity $[14,15]$. The chemical activated bentonite has been widely studied [16-18]. The bentonite chemically modified has been widely applied as sorbents for toxic substances such as $\mathrm{Pb}$ (II) [19], dye [20, 21], picoline [22], phosphates [23] and for catalytic alkylation of benzene [24]. However no sorption study has yet been published on the removal of chlorothalonil as a commercial compound used in agriculture by local bentonite. The chlorothalonil is an inhibitor of spore germination, which acts on various enzymes and on the metabolism of fungi. It can seep into the aquatic environment by means of spray and runoff. However it is possible that the chlorothalonil affect human health through exposure to food and water contaminated by this substance [25]. 
The present work deals with the acid activation of an Algerian bentonite (M'zila deposit) and testing of his capacity to remove the chlorothalonil fungicide in aqueous solution by adsorption. The hydrochloric acid solutions were used in the concentration range of $0.1-6 \mathrm{~N}$. The physicochemical parameters of raw and activated materials were also determined using the data obtained from the adsorption experiments.

\section{Materials and methods}

\subsection{Materials}

Bentonite used in this study comes from M'zila deposit in Mostaganem (western Algeria). This material is commercialized without additives by BENTAL society. Before the experiments, the samples were purified and sieved at $80 \mu \mathrm{m}$. Cation exchange capacity (CEC) of natural bentonite was determined to be $48 \mathrm{meg} / 100 \mathrm{~g}$ by applying the conductimetric titration method [26]. The point of zero charge (PZC) of purified bentonite was found as $c a$. 6.8 by the solid addition method [27].

The product chlorothalonil (Chl) fungicide was obtained by Syngenta Protection of Plants S.A, Bale, Switzerland. It contains $400 \mathrm{~g} / \mathrm{L}$ of chlorothalonil in the form of concentrated suspension with some impurities. The chemical formula of $\mathrm{Chl}$ is $\mathrm{C}_{8} \mathrm{Cl}_{4} \mathrm{~N}_{2}$, and its molecular weight is $265.93 \mathrm{~g} / \mathrm{mol}$. The IUPAC name of Chl is 2, 4, 5, 6tetrachloro-1, 3-benzenedicarbonitrile. The solubility of chlorothalonil in water is $0.6 \mathrm{mg} / \mathrm{L}$ at $293 \mathrm{~K}$. The chemical structure of chlorothalonil molecule is shown in Table 1.

Table 1: The chemical composition of raw bentonite and chemical structure of chlorothalonil.

\begin{tabular}{lll}
\hline Sample & Percentage \% & Structure of Chl \\
\hline $\mathrm{SiO}_{2}$ & 64.22 & \\
$\mathrm{Al}_{2} \mathrm{O}_{3}$ & 11.62 & \\
$\mathrm{CaO}$ & 09.33 & \\
$\mathrm{MgO}$ & 03.47 & \\
$\mathrm{Fe}_{2} \mathrm{O}_{3}$ & 04.88 & \\
$\mathrm{TiO}_{2}$ & 01.06 & \\
$\mathrm{Na}_{2} \mathrm{O}$ & 03.38 & \\
$\mathrm{SO}_{3}$ & 0.46 & \\
$\mathrm{P}_{2} \mathrm{O}_{5}$ & 0.03 & \\
L.I. & 1.55 & \\
\hline \multicolumn{3}{c}{ L.I.: loss on Ignition }
\end{tabular}

\subsection{Materials characterization}

The chemical analysis of natural bentonite was performed with X-fluorescence XRF 9900, Thermo instrument. The specific surface area was determined by adsorption of nitrogen at $77 \mathrm{~K}$ by BET method via a Quantachrome instruments. X-ray analyses were performed using INEL CPS 120 diffractometer employing cobalt K $\alpha$ radiation $(\lambda=0.178 \mathrm{~nm})$ operating at $40 \mathrm{kV}$ and $25 \mathrm{~mA}$ with a fixed slit. The absorbance measurements of chlorothalonil were made with a spectrophotometer (VIS 7220 G, Biotech Engineering Management) at the $\lambda_{\max }=360 \mathrm{~nm}$.

\subsection{Acid activation of bentonite}

Raw bentonite was treated by hydrochloric acid $(\mathrm{HCl})(37 \%$ purity, Merck) at different concentrations $(0.1,1$ and 6 $\mathrm{N})$ at $343 \mathrm{~K}$. The amounts of $4 \mathrm{~g}$ of each treated sample were added to $400 \mathrm{~mL}$ of acid solution [16]. The contact time of the samples with the acid solution was fixed as 4 and $24 \mathrm{~h}$. At the end of treatment, the bentonite was washed several times with distilled water and dried over night at $353 \mathrm{~K}[28,29]$.

\subsection{Adsorption experiment}

The Chlorothalonil was prepared in the range of initial concentrations $100-500 \mathrm{mg} / \mathrm{L}$, in order to know the maximum amount of fungicide that clay can adsorb. For each experiment, $20 \mathrm{~mL}$ of pesticide solution was added to $0.1 \mathrm{~g}$ of the raw clay. The suspension was shaken at room temperature $(296 \pm 0.5 \mathrm{~K})$ for $3 \mathrm{~h}$. The $\mathrm{pH}$ was adjusted at 3-4 by the addition of $1 \mathrm{~N} \mathrm{NaOH}$ or $1 \mathrm{~N} \mathrm{HCl}$ solutions. When adsorption procedure completed, the mixture was centrifuged at $4000 \mathrm{rpm}$ to get supernatant liquid. The amount of Chl retained by the adsorbent was calculated using the following equation:

$q_{e}=\left(C_{0}-C_{e}\right) \cdot \frac{V}{m}$

where, $q_{\mathrm{e}}$ is the equilibrium adsorption capacity $(\mathrm{mg} / \mathrm{g}), C_{0}$ and $C_{e}$ are the initial and equilibrium pesticide concentrations $(\mathrm{mg} / \mathrm{L})$, respectively, $V$ is the volume of solution $(\mathrm{L})$ and $m$ is the mass of the adsorbent $(\mathrm{g})$. 


\subsection{Adsorption Isotherms}

The Langmuir sorption isotherm which is valid for monolayer adsorption onto a surface containing a finite number of identical sites has been widely used to characterise the adsorption phenomena from solution. The Langmuir isotherm can be represented by the following equation [30, 31]:

$q_{e}=Q_{0} \cdot \frac{K_{L} C_{e}}{1+K_{L} C_{e}}$

Equation (2) can also be represented by the linear form below:

$\frac{C_{e}}{q_{e}}=\frac{C_{e}}{Q_{0}}+\frac{1}{K_{L} Q_{0}}$

where $Q_{0}$ is the maximum adsorption capacity $(\mathrm{mg} / \mathrm{g})$, and $K_{L}(\mathrm{~L} / \mathrm{mg})$ is a constant that relates to the heat of adsorption.

Freundlich isotherm represents satisfactorily the sorption data at low and intermediate concentrations on heterogeneous surfaces [32]. The Freundlich model may be expressed in the form below:

$q_{e}=K_{F} C_{e}^{\frac{1}{n}}$

Equation (4) can also be expressed in linear form below:

$\log q_{e}=\log K_{F}+\frac{1}{n} \log C_{e}$

where $K_{F}\left((\mathrm{~L} / \mathrm{mg})^{1 / n}\right)$ and $n$ are the Freundlich constants, indicating the capacity and intensity of adsorption, respectively.

\subsection{Adsorption kinetics}

The data obtained from adsorption experiments of chlorothalonil onto activated bentonite were evaluated by pseudo-first and pseudo-second order models. The linear form of pseudo-first order rate equation is given by [33,34]:

$\ln \left(q_{e}-q_{t}\right)=\ln q_{e}-k_{1} t$

where $q_{t}$ is the amount adsorbed $(\mathrm{mg} / \mathrm{g})$ at time $t, k_{l}$ is the rate constant $\left(\mathrm{min}^{-1}\right)$. The value of $k_{l}$ was calculated by plots $\ln \left(\mathrm{q}_{\mathrm{e}}-\mathrm{q}_{\mathrm{t}}\right)$ versus $t$ drawn at different concentrations.

The pseudo-second-order kinetic model equation may be expressed by the following equation [35,36]:

$\frac{t}{q_{t}}=\frac{1}{k_{2} q_{e}^{2}}+\frac{t}{q_{e}}$

where $k_{2}$ is the rate constant of the adsorption process $\left(\mathrm{min}^{-1}\right)$. Plots of $\mathrm{t} / \mathrm{q}_{\mathrm{t}}$ against $t$ for the adsorption of Chl onto bentonite are drawn to obtain the rate parameters.

\subsection{Thermodynamic study}

Thermodynamic parameters of the adsorption of Chl onto treated bentonite at 303, 313 and $323 \mathrm{~K}$ were calculated using the following equation [37,38]:

$\ln K_{d}=\frac{\Delta S^{0}}{R}-\frac{\Delta H^{0}}{R T}$

The distribution coefficient $\mathrm{K}_{\mathrm{d}}(\mathrm{L} / \mathrm{g})$ is calculated from the following equation:

$K_{d}=\frac{\left(C_{0}-C_{e}\right)}{C_{e}} \cdot \frac{V}{m}$

where $\Delta H^{\circ}, \Delta S^{\circ}$, and $T$ are the adsorption enthalpy $(\mathrm{kJ} / \mathrm{mol})$, entropy $(\mathrm{J} / \mathrm{mol} . \mathrm{K})$ and temperature in Kelvin, respectively, and $R$ is the gas constant $(8.31 \mathrm{~J} / \mathrm{mol} . \mathrm{K})$. The slope and intercept of the plot of $\ln \mathrm{K}_{\mathrm{d}}$ versus $1 / \mathrm{T}$ correspond to $\Delta H^{\circ} / R$ and $\Delta S^{\circ} / R$, respectively.

The Gibbs free energy, $\Delta \mathrm{G}^{\circ}(\mathrm{kJ} / \mathrm{mol})$, of specific adsorption is represented by the following equation [39]:

$\Delta G^{0}=\Delta H^{0}-T \Delta S^{0}$

\section{Results and discussion}

\subsection{Characterization of the adsorbent}

The chemical composition of natural bentonite showed in Table 1 is presents as follows: the silica, alumina and lime are the major oxides of the sample and the trace elements such as iron, magnesium, sodium, titanium, sulphate and phosphor oxides exist as impurities. 
The specific surface area of natural bentonite $(\mathrm{BN})$, bentonite treated by $1 \mathrm{~N}(\mathrm{BA} 1 \mathrm{~N})$ and $6 \mathrm{~N}(\mathrm{BA} 6 \mathrm{~N})$ hydrochloric acid were determined as $59,82.22$ and $80.55 \mathrm{~m}^{2} / \mathrm{g}$, respectively. We see that the specific surface areas of both activated bentonites are almost identical, which are much higher than that of the raw bentonite. The specific surface area greatly increases at the acid concentration of $1 \mathrm{~N}$, but slightly decreases at the concentrations higher than this value and then does not change much. Similar result were found by activating bentonite with sulphuric acid, where the surface area decreases were observed by treating clay up to $3 \mathrm{M} \mathrm{H}_{2} \mathrm{SO}_{4}$ [40] and $6 \mathrm{M} \mathrm{H}_{2} \mathrm{SO}_{4}$ [13], respectively.

The XRD patterns of raw and activated bentonites at various concentrations $(0.1,1$ and $6 \mathrm{~N})$ were shown in Fig. 1. The untreated sample contains some mineral phases concerning montmorillonite (M), kaolinite (K), illite (I), quartz (Q), calcite (C) and dolomite (D).
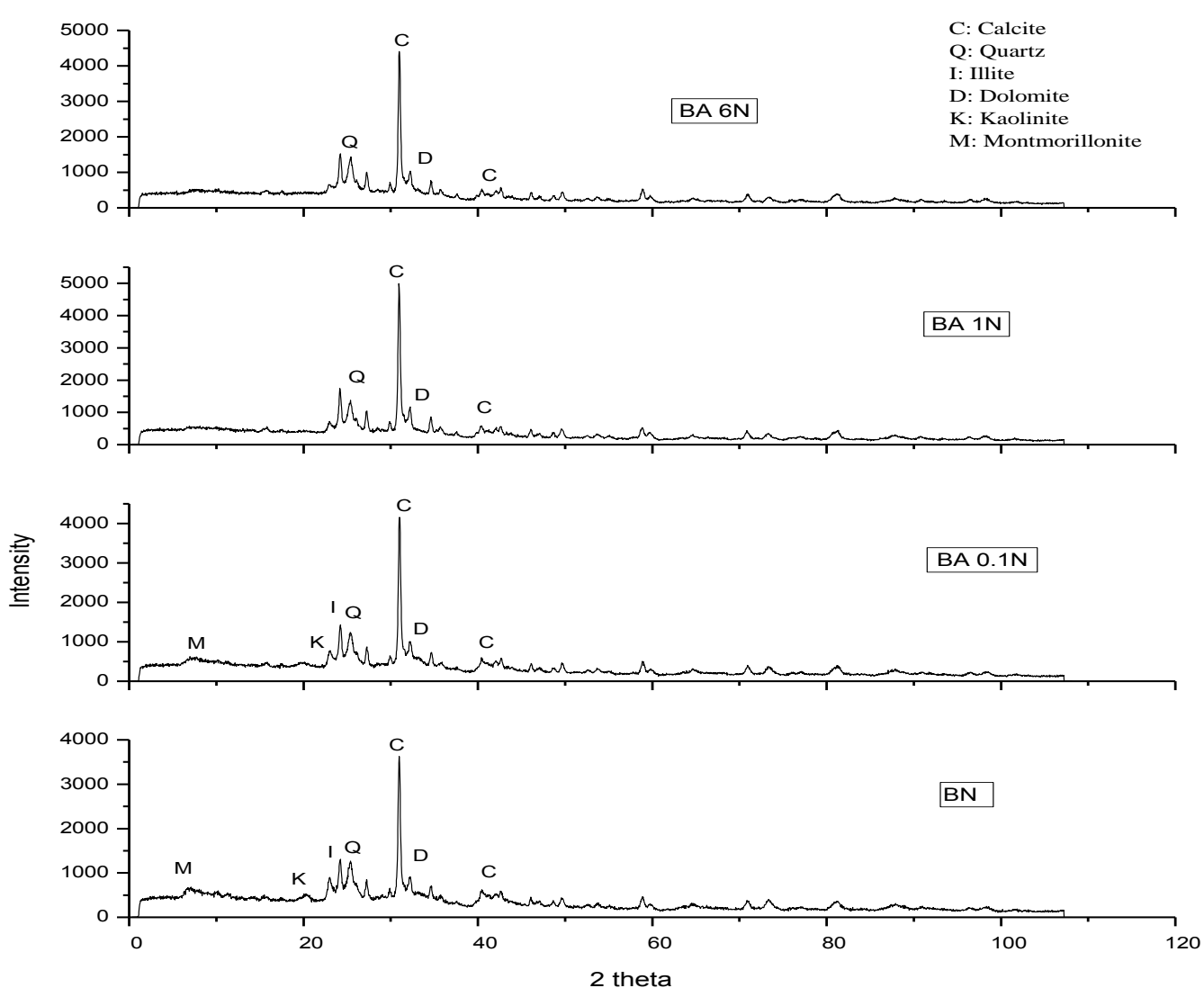

Figure 1: XRD patterns of raw and activated bentonites

We note that there is no difference between the spectra of $\mathrm{BN}$ and $\mathrm{BA}(0.1)$. The concentration of $0.1 \mathrm{~N}$ seems not be sufficient to make significant changes in the structure of bentonite. This means that it is a cation exchange causing the substitution of the exchangeable cations of interlayer space by protons $\mathrm{H}^{+}$. In contrast to the sample treated with $0.1 \mathrm{~N}$, the samples BA. $1 \mathrm{~N}$ and BA. $6 \mathrm{~N}$ undergo a significant structural modification according to the XRD spectra, where we notice that the peaks of montmorillonite and the kaolinite almost disappeared, while that of the illite is reduced in intensity. So from $1 \mathrm{~N}$ concentration of $\mathrm{HCl}$, the clay minerals of bentonite are exposed to the direct effect of acid leading to the destruction of the basic clay sheets. Treatment of clay with high concentration of acid solution can often results in the replacement of the exchangeable cations with $\mathrm{H}^{+}$and $\mathrm{Al}^{3+}$ ions and the release of the other cations from tetrahedral and octahedral sites, leaving $\mathrm{SiO}_{4}$ groups largely intact [41]. This process generally increases the surface area and the acidity of the clay minerals [42].

\subsection{Effect of $p H$}

The $\mathrm{pH}$ is an important factor affecting the adsorption studies, through changing the surface charge of adsorbent. In our study we follow the change of $\mathrm{pH}$ with the adsorption of pesticide by the treated bentonite samples, for an initial concentration about $30 \mathrm{mg} / \mathrm{L}$. Figure 2 shows that, the adsorption onto BN and BA $1 \mathrm{~N}$ samples occurs weakly in basic medium. There is a significant increase in the adsorbed amount of $\mathrm{Chl}$ in acid solution. The maximum adsorption onto the natural bentonite took place between $\mathrm{pH} 2$ and 3, whereas for activated bentonite it was reached between $\mathrm{pH} 3$ and 4. 


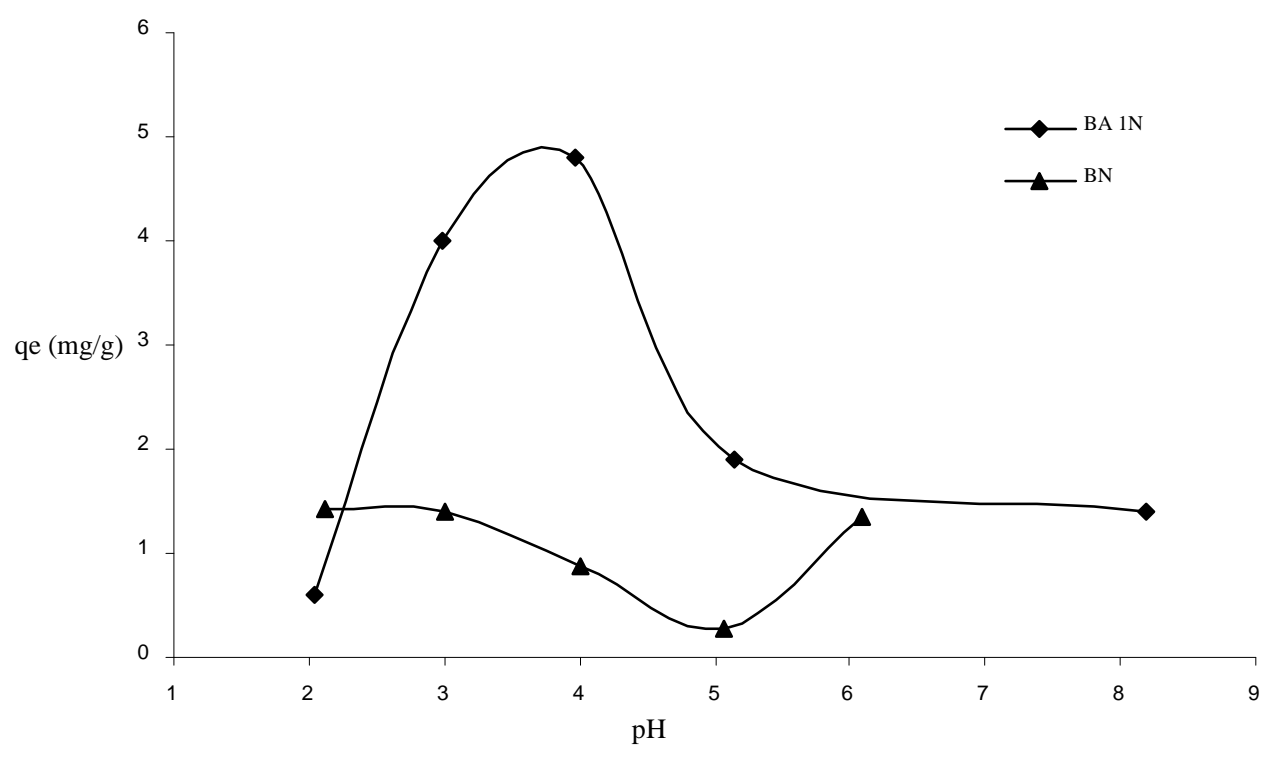

Figure 2: Effect of $\mathrm{pH}$ on adsorbed amount of $\mathrm{Chl}$ onto the bentonite

\subsection{Effect of contact time}

To determine the optimum contact time and to study the adsorption kinetics, the adsorption of Chl on a series of samples in the time range 2-180 min was studied. The concentration of Chl was fixed at $60 \mathrm{mg} / \mathrm{L}$ in $20 \mathrm{ml}$ volume of solution, into which $0.1 \mathrm{~g}$ of treated bentonite was added. Figure 3 shows that the Chl adsorption increased in parallel with the contact time, and over $80 \%$ of removal $\mathrm{Chl}$ was performed by modified bentonite in $50 \mathrm{~min}$. The adsorption is facile in the early stage of the process and became slower over time to reach equilibrium eventually. The equilibrium time for the two adsorbents was determined to be $60 \mathrm{~min}$.

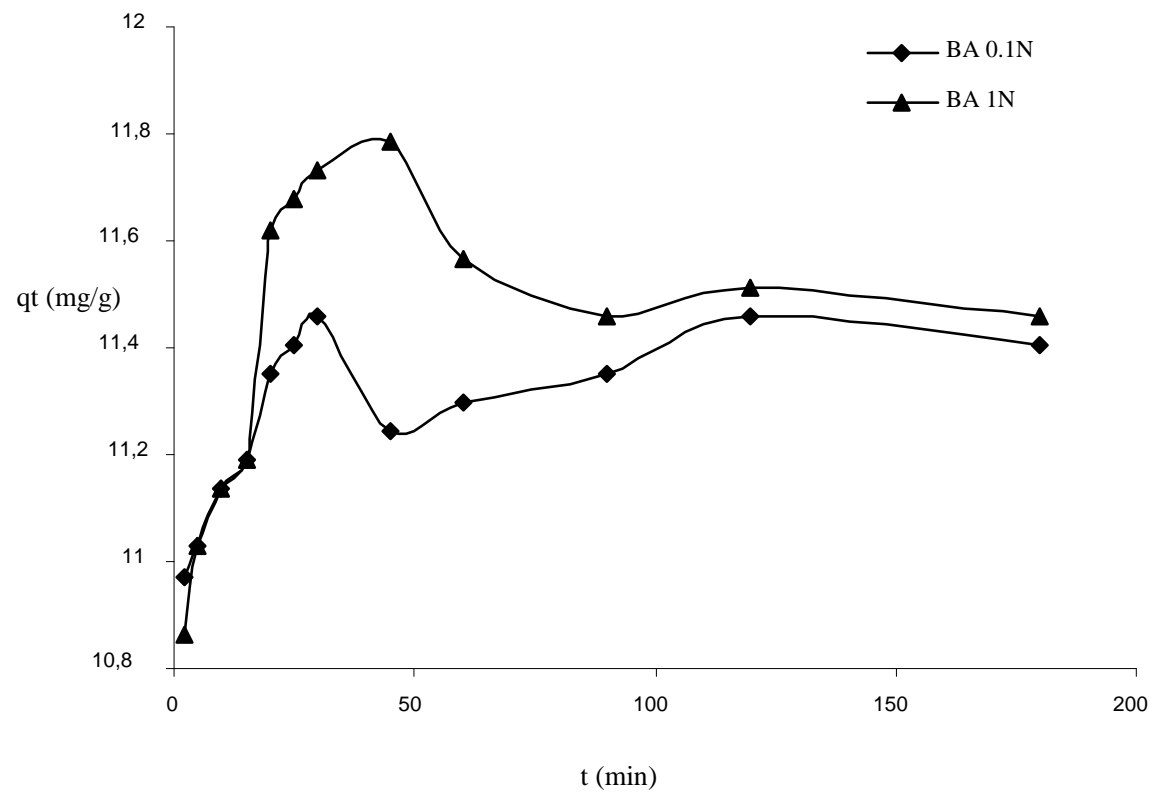

Figure 3: Effect of contact time on adsorbed amount of Chl onto activated bentonites

\subsection{Adsorption isotherms}

The adsorption isotherms were obtained for different initial concentrations of chlorothalonil in solution for the duration of 3 hours at $296 \mathrm{~K}$. To obtain the adsorption isotherms, amounts of $\mathrm{Chl}$ adsorbed by the samples were plotted versus equilibrium concentration values. The figures 4 and 5 show the adsorption of Chl by the activated bentonite for $4 \mathrm{~h}$ and $24 \mathrm{~h}$, respectively.

These figures show that the adsorbed amount of Chl onto raw and activated bentonite increases in parallel with the equilibrium concentration. The experimental isotherm obtained here may be classified as type $\mathrm{S}$ referring to the classification of Giles et al. [43]. This type of isotherm originates from the cooperative isothermal adsorption, i.e. the adsorbed molecules promote higher adsorption of other molecules and tend to be adsorbed in groups [44]. 
We note also that the activated bentonite adsorbs much better than the natural bentonite. When the activated samples were compared, it was found that the maximum amount of adsorption $(42.88 \mathrm{mg} / \mathrm{g})$ was observed for BA $1 \mathrm{~N}$ for $24 \mathrm{~h}$. Similar results were reported by Ma et al. [45] for the removal of anionic pollutants by activated bentonite. For the next experiments, we use only the BA $1 \mathrm{~N}$ samples as adsorbents for $24 \mathrm{~h}$.

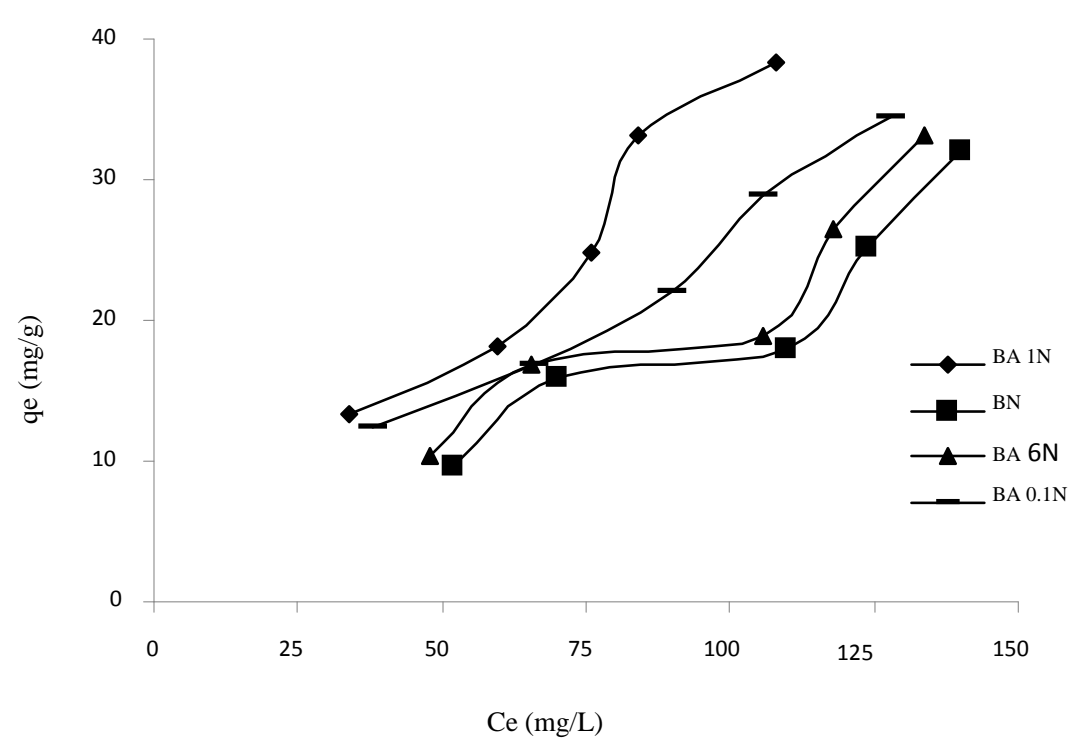

Figure 4: Adsorption isotherms of Chl onto activated bentonite for $4 \mathrm{~h}$

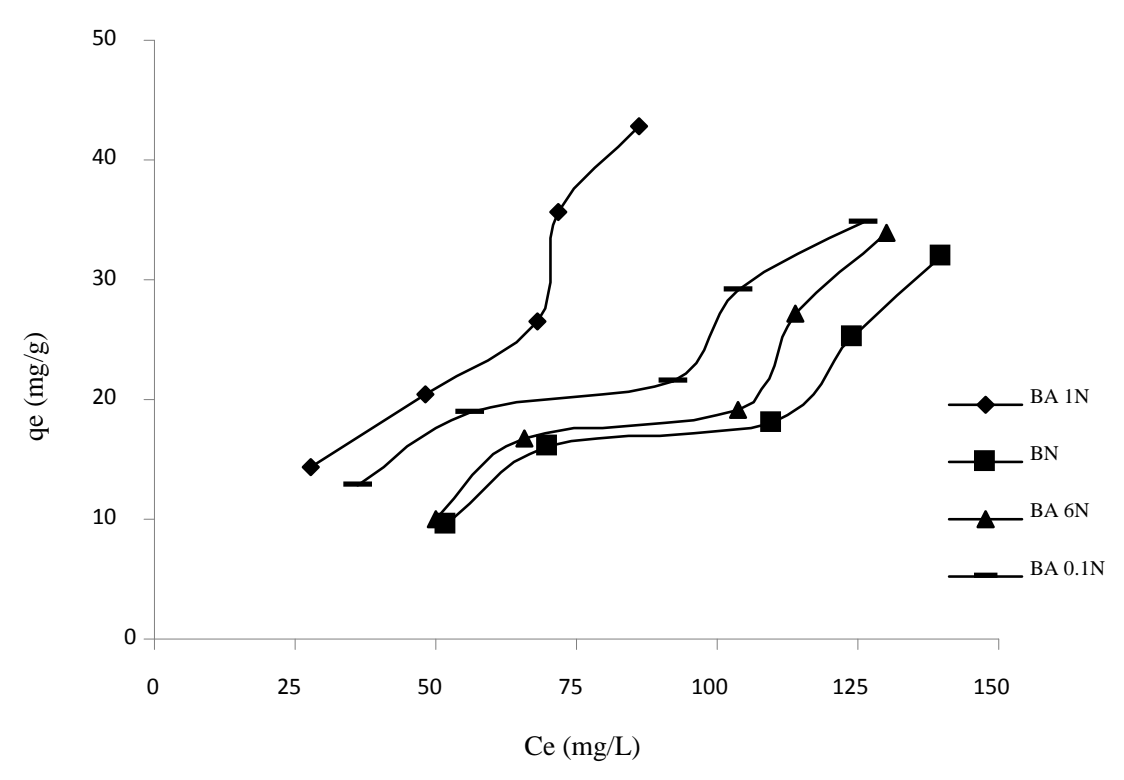

Figure 5: Adsorption isotherms of Chl onto activated bentonite for $24 \mathrm{~h}$

The effects of temperature on the adsorption of chlorothalonil by BA $1 \mathrm{~N}$ were examined at 303,313 and $323 \mathrm{~K}$, and the data obtained were plotted in Fig. 6. The adsorption capacities increase with increased temperature. The adsorbed amount of Chl by BA $1 \mathrm{~N}$ at $323 \mathrm{~K}$ is $51.61 \mathrm{mg} / \mathrm{g}$. This means that the adsorption of Chl onto the activated bentonite is favourable at high temperature. This can be confirmed later by thermodynamic study, which the process of adsorption was more spontaneous when increasing temperature. The enhancement in the adsorption capacity might be due to the chemical interaction between adsorbate and adsorbent, creation of some new adsorption sites, or the increased rate of intra-particle diffusion of adsorbate molecules into the pore structure of the acid-activated bentonite at higher temperatures [46]. Similar results have been reported by Rawajfih and Nsour which are found that the Picoline adsorption by acid activated bentonite increased with increasing solution temperature from 303 to $333 \mathrm{~K}$ [22]. 
We applied the Langmuir model for the data obtained at different temperatures and we found that the results which were not mathematically consistent with the Langmuir equation were considered to be insignificant in terms of adsorption. Therefore, they have not been presented here. However, the Freundlich model represented the adsorption data better than the Langmuir model, and the obtained parameters of Freundlich model were given in Table 2. The values of correlation coefficient $\mathrm{R}^{2}$, are close to unit value, proving good fitting of the data by this model. According to the Freundlich theory, the multilayer formation on the adsorbent surface is likely and the sites are heterogeneous with different fixation energies.

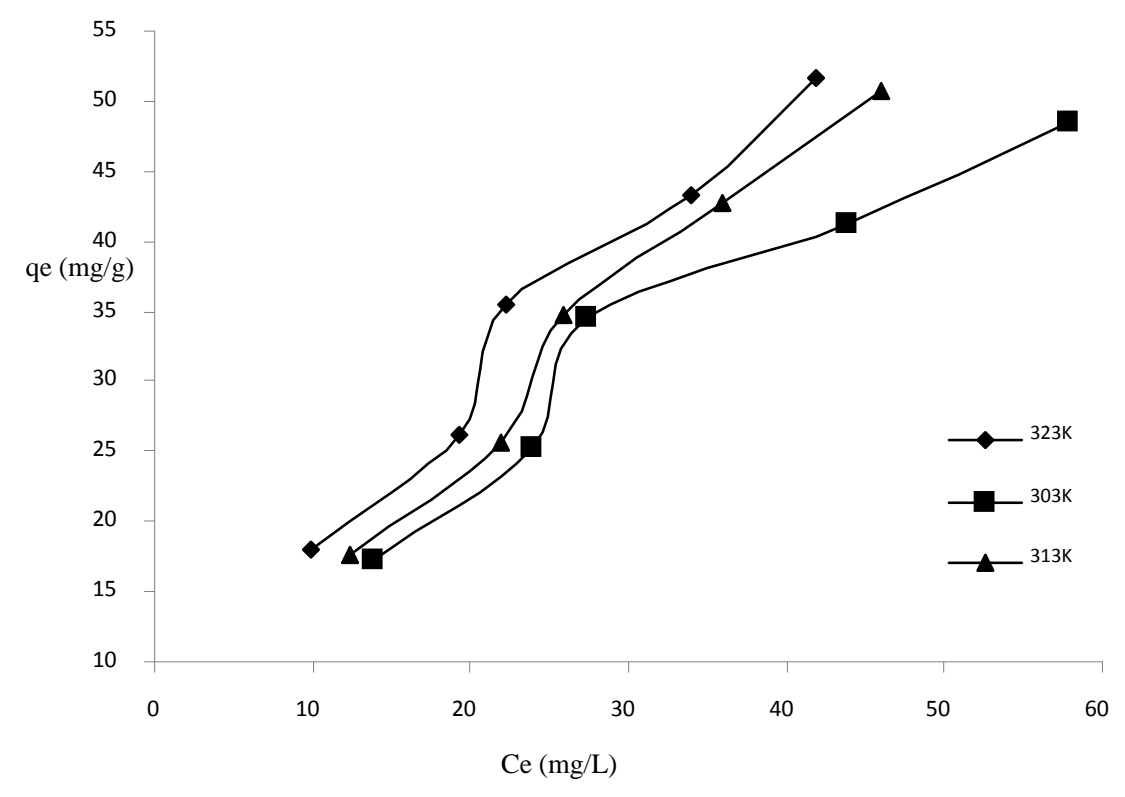

Figure 6: Adsorption isotherms of Chl onto BA $1 \mathrm{~N}$ for $24 \mathrm{~h}$ at different temperatures

Table 2: The constants of Freundlich model.

\begin{tabular}{lllll}
\hline Sample & $\mathrm{T}(\mathrm{K})$ & $\begin{array}{l}\mathrm{K}_{\mathrm{F}} \\
\left(\mathrm{mg} / \mathrm{g}(\mathrm{L} / \mathrm{mg})^{1 / \mathrm{n}}\right)\end{array}$ & $1 / \mathrm{n}$ & $\mathrm{R}^{2}$ \\
\hline BA 0.1N & 296 & 0.913 & 0.737 & 0.935 \\
\hline & 296 & 0.590 & 0.939 & 0.925 \\
BA 1N & 303 & 2.064 & 0.725 & 0.950 \\
& 313 & 2.295 & 0.831 & 0.979 \\
& 323 & 2.087 & 0.736 & 0.970 \\
\hline
\end{tabular}

\subsection{Adsorption kinetics}

To evaluate the adsorption rate, the adsorption kinetic was examined by pseudo-first order and pseudo-second order models. The results obtained were listed in Table 3. We see that the correlation coefficient for pseudo-second order is almost equal to unit value. This means that for the rate constants of the adsorption of Chl on all activated bentonite samples are better represented by pseudo-second order model.

Table 3: Parameters of pseudo-first order and pseudo-second order kinetics models.

\begin{tabular}{lllllll}
\hline \multicolumn{3}{c}{ Pseudo-first order } & \multicolumn{5}{c}{ Pseudo-second order } \\
\hline & qe (mg/g) & $\mathrm{k}_{1}\left(\mathrm{~min}^{-1}\right)$ & $\mathrm{R}^{2}$ & $\mathrm{qe}(\mathrm{mg} / \mathrm{g})$ & $\mathrm{k}_{2}(\mathrm{mg} / \mathrm{g} \mathrm{min})$ & $\mathrm{R}^{2}$ \\
\hline BA 1N & 1.51 & 0.106 & 0.917 & 11.52 & 0.28 & 0.999 \\
\hline
\end{tabular}

\subsection{Adsorption heats}

In the case of adsorption of molecules on a solid surface, the Gibbs energy is composed of two functions, the enthalpy function $(H)$, which is measure of the energy of interaction between the molecules and the adsorbent surface, and the entropy function $(S)$, which reflects the change and the arrangement of molecules in the liquid phase and on the surface. It can be seen from Table 4 that the calculated $\Delta G^{\circ}$ values have negative signs, indicating 
that the adsorption process is spontaneous in the experimental temperature range. All $\Delta H^{\circ}$ values are positive, showing that the adsorption process is endothermic, and higher temperature is in favour of the adsorption process.

Table 4: Thermodynamic parameters of the adsorption of Chl onto activated bentonite.

\begin{tabular}{llllllll}
\hline & \multirow{2}{*}{$\mathrm{C}_{0}(\mathrm{mg} / \mathrm{L})$} & $\Delta \mathrm{H}^{\circ}(\mathrm{kJ} / \mathrm{mol})$ & \multirow{2}{*}{$\Delta \mathrm{S}^{\circ}(\mathrm{J} / \mathrm{molK})$} & \multicolumn{4}{l}{$\Delta \mathrm{G}^{\circ}(\mathrm{kJ} / \mathrm{mol})$} \\
\cline { 5 - 7 } & & & & $303 \mathrm{~K}$ & $313 \mathrm{~K}$ & $323 \mathrm{~K}$ & $\mathrm{R}^{2}$ \\
\hline \multirow{4}{*}{ BA 1N } & 30 & 68.894 & 234.292 & -2.096 & -4.439 & -6.782 & 0.930 \\
& 40 & 34.020 & 120.528 & -2.499 & -3.705 & -4.910 & 0.895 \\
& 50 & 29.726 & 107.381 & -2.810 & -3.883 & -4.957 & 0.927 \\
& 60 & 39.861 & 137.879 & -1.915 & -3.294 & -4.673 & 0.926 \\
& 80 & 40.422 & 141.319 & -2.397 & -3.810 & -5.223 & 0.910 \\
\hline
\end{tabular}

\section{Conclusions}

The bentonite, a natural and local clay mineral, can be effectively used as an adsorbant for the removal of fungicide as chlorothalonil from the wastewater. The raw bentonite consisted of the fine particles of some minerals as montmonrillonite, kaolinite, illite, quartz, calcite and dolomite according to the XRD analyses. The raw bentonite was treated at various normalities of hydrochloric acid solution for 4 and 24 hours. The results of treatment indicated that the clay sheets were affected significantly up to the acid concentration of $1 \mathrm{~N}$, and the specific surface area increased in parallel with the acid concentration. The investigations showed there is no significant structural modification between the samples treated with $1 \mathrm{~N}$ of hydrochloric acid and those treated with $6 \mathrm{~N}$. The specific surface areas of BA $1 \mathrm{~N}$ and BA $6 \mathrm{~N}$ were almost identical.

The amounts adsorbed of chlorothalonil by activated bentonites were more that the raw bentonite and they increased with increasing temperature and decreasing $\mathrm{pH}$. The Freundich model described the experimental data better comparing to the Langmuir model because after the chemically treatment of bentonite, the surfaces solids are not homogenous with existing of the different energy sites. The adsorption of chlorothalonil onto the activated bentonites followed the pseudo-second order kinetic model. The thermodynamic parameters showed that the adsorption of the fungicide is an endothermic and spontaneous process.

\section{References}

1. Taha S.M., Amer M.E., Elmarsafy A.E., Elka M.Y., J. Environ. Chem. Eng. 2 (2014) 2013.

2. Oerke E.C., Dehne H.W., Eur. J. Plant Pathol. 103 (1997) 203.

3. Apera C., Terezoni B., De Angelis V., Sciarra G., Lunghini L.G.B., Vasconi D., Fani D., Quercia A., Salvan A., Settime L., Arch. Env. Contam. Toxicol. 48 (2004) 127.

4. El-Bakouri H., Usero J., Morillo J., Rojas R., Ouassini A., Bioresour. Technol. 100 (2009) 2676.

5. Anwar S., Liaquat F., Khan Q.M., Khalid Z.M., Iqbal S., J. Hazard. Mater. 168 (2009) 400.

6. Kitous O., Cheikh A., Lounici H., Grib H., Pauss A., Mameri N, J. Hazard. Mater. 161 (2009) 1035.

7. Crini G., Bioresour. Techn. 60 (2006) 67.

8. Luckham P.F., Rossi S., Adv. Colloid Interface Sci. 82 (1999) 43.

9. Wu R.J., Chen C.C., Chen M.H., Lu C.S., J. Hazard. Mater. 162 (2009) 945.

10. Ahmad A.L., Tan L.S., Shukor S.R.A., J. Hazard. Mater. 154 (2008) 633.

11. Bouazizi A., Saja S., Achiou B., Ouammou M., Calvo J.I., Aaddane A., Alami Younssi S., Appl. Clay Sci. 132 (2016) 33.

12. Komadel P., Clay Min. 38 (2003) 127.

13. Caglar B., Afsin B., Koksal E., Tabak A., Eren E., Quim. Nova 36 (2013) 955.

14. Mokaya R., Jones W., J. Catal. 153 (1995) 76.

15. Mokaya R., Jones W., Davies M.E., Whittle M.E., J. Am. Oil Chem. Soc. 70 (1993) 241.

16. Bieseki L., Treichel H., Araujo A.S., Castellã Pergher S.B., Appl. Clay Sci. 85 (2013) 46.

17. Steudel A., Batenburg L.F., Fischer H.R., Weidler P.G., Emmerich K., Appl. Clay Sci. 44 (2009) 95.

18. Woumfo D., Kamga R., Figueras F., Njopwouo D., Appl. Clay Sci. 37 (2007) 149.

19. Bhattacharyya K.G., Gupta S.S., Colloids Surf. A: Physicochem, Eng. Aspects 277 (2006) 191.

20. Manjot T., Jin B., Chem. Eng. J. 187 ( 2012) 79.

21. Zahaf F., Dali N., Marouf R., Ouadjenia F., Schott J., Desalin. water treat. 57 (2016) 21045.

22. Rawajfih Z., Nsour N., Appl. Clay Sci. 47 (2010) 421.

23. Pawar R.R., Gupta P., Lalhmunsiama, Bajaj H.C., Lee S-M., Sci. Total Environ. 572 (2016) 1222.

24. Faghihian H., Mohammadi M.H., Appl. Clay Sci. $93-94$ (2014) 1.

25. Fletcher, J.S., Nellessen, J.E., Pfleeger T.G.. Environ. Toxicol. Chem. 13 (1994) 1383. 
26. Navia R., Environmental use of volcanic soil as natural adsorption material, $\mathrm{PhD}$ Thesis, University of Leoben, Austria, (2004).

27. Srivastava V.C, Mall I.D., Mishra I.M., J. Hazard. Mater. 134 (2006) 257.

28. Eloussaief M., Benzina M., J. Hazard. Mater. 178 (2010) 753.

29. Novaković T., Rõzić L., Petrović S., Rosić A., Chem. Eng. J. 137 (2008) 436.

30. Langmuir I., J. Am. Chem. Soc. 40 (1918) 1361.

31. Sawalha M.F., Peralta-Videa J.R., Romero-Gonzalez J., Gardea-Torresdey J.L., J. Colloid Interface Sci. 300 (2006) 100.

32. Freundlich H.M.F., Z. Phys. Chem. 57 (1906) 385.

33. Lagergren S., Svenska B.K., Veternskapsakad Handlingar 4 (1898) 1.

34. Ho Y.S., Scientometrics 59 (2004) 171.

35. Azizian S., J. Colloid Interface Sci. 276 (2004) 47.

36. Ho Y.S., McKay G., Chem. Eng. J. 70 (1998) 115.

37. Fan Q.H., Shao D.D., Hu J., Wu W.S., Wang X.K., Surf. Sci. 602 (2008) 778.

38. Wang X.K., Chen C.L., Hu W.P., Ding A.P., Xu D., Zhou X., Environ. Sci. Technol. 39 (2005) 2856.

39. Chion M.S., Ho P.Y., Li H.Y., Dye Pigment 60 (2004) 69.

40. Tomić Z.P., Logar V.P., Babic B.M., Rogan J.R., Makreski P., Spectrochimica Acta Part A 82 (2011) 389.

41. Ravichandran J., Sivasankar B., Clays Clay Miner. 45 (1997) 854.

42. Bhattacharyya K.G., Gupta S.S., Adv. Colloid Interface Sci. 140 (2008) 114.

43. Giles C.H., MacEwan T.H., Nakhwa S.N., Smith D., J. Chem. Soc. (1960) 3973.

44. N.N. Lichtin, M. Avudaithai, E. Berman, J. Dong, Res. Chem. Interm. 20 (1994) 755.

45. Ma J., Qi J., Yao C., Cui B., Zhang T., Li D., Chem. Eng. J. 202 (2012) 97.

46. Karthikeyan T., Rajgopal S., Miranda L.R., J. Hazard. Mater 124 (2005) 192.

\section{(2017) ; http://www.jmaterenvironsci.com}

